\title{
Research Article \\ Effects of Green Tea Extracts on the Pharmacokinetics of Quetiapine in Rats
}

\author{
Essam Ezzeldin, ${ }^{1,2}$ Yousif A. Asiri, ${ }^{3}$ and Muzaffar Iqbal ${ }^{1,2}$ \\ ${ }^{1}$ Department of Pharmaceutical Chemistry, College of Pharmacy, King Saud University, Riyadh 11451, Saudi Arabia \\ ${ }^{2}$ Bioavailability Laboratory, College of Pharmacy, King Saud University, Riyadh 11451, Saudi Arabia \\ ${ }^{3}$ Department of Clinical Pharmacy, College of Pharmacy, King Saud University, Riyadh 11451, Saudi Arabia
}

Correspondence should be addressed to Muzaffar Iqbal; muziqbal@gmail.com

Received 2 October 2014; Accepted 29 December 2014

Academic Editor: Alvin J. Beitz

Copyright (c) 2015 Essam Ezzeldin et al. This is an open access article distributed under the Creative Commons Attribution License, which permits unrestricted use, distribution, and reproduction in any medium, provided the original work is properly cited.

\begin{abstract}
Quetiapine is an atypical antipsychotic, used clinically in the treatment of schizophrenia, acute mania in bipolar disorders, and bipolar depression in adults. In this study, the effect of green tea extracts (GTE) on the pharmacokinetics of quetiapine (substrate of CYP3A4) was investigated in rats. Male Wistar albino rats received GTE (175 mg/kg) or saline (control) by oral gavage for 7 days before a single intragastric administration of $25 \mathrm{mg} / \mathrm{kg}$ quetiapine. Plasma concentrations of quetiapine were measured up to $12 \mathrm{~h}$ after its administration by a validated ultraperformance liquid chromatography-tandem mass spectroscopy. Pretreatment with GTE produced significant reductions in the maximum plasma concentration and area under the curve of quetiapine by $45 \%$ and $35 \%$, respectively, compared to quetiapine alone. However, GTE did not produce significant change in elimination half-life and oral clearance of quetiapine. This study concluded that GTE may decrease the bioavailability of quetiapine when coadministered.
\end{abstract}

\section{Introduction}

Consumption of green tea (Camellia sinensis) as beverages and dietary supplements is a common practiced habit worldwide. It contains high amount of the potent antioxidants polyphenols and has been associated with significant beneficial effects on human health including cardiovascular disease, cancer, obesity, and infection [1-7]. The results of in vitro studies suggest that green tea extracts (GTE) and/or the catechins, which are believed to be the major polyphenols of green tea, may affect the disposition of drugs by modulating the activities of drug metabolizing enzymes like CYP3A and uptake or efflux transporters, for example, P-glycoprotein (Pgp) [8-13]. These in vitro studies results were also supported by in vivo experiments in which GTE and/or epigallocatechin gallate (EGCG) exhibit significant pharmacokinetic interaction with coadministered drugs [13-20].

Quetiapine (QUE), a dibenzothiazepine derivative, is an atypical antipsychotic, indicated for the treatment of schizophrenia, acute mania in bipolar disorders, and bipolar depression in adults. It has been found to be effective as a monotherapy and as an adjunctive to a mood stabilizer [21-23]. After oral administration, QUE is rapidly absorbed with peak plasma concentrations achieved ranging from 1 to 2 hours. The absolute bioavailability of QUE is unknown in human, although it was lower than $10 \%$ in rats and monkeys and 8 to $30 \%$ in dogs, respectively, consequent to an extensive first pass effect. Plasma protein binding is approximately $83 \%$ and it exhibits linear pharmacokinetics in the clinical dose range $[24,25]$. QUE is extensively metabolized by the cytochrome P450 (CYP) isoenzyme 3A4; hence coadministration of CYP 3A enzyme inducer, for example, phenytoin and thioridazine, increases the oral clearance of QUE whereas coadministration of ketoconazole and cimetidine (CYP 3A enzyme inhibitors) reduces it [26-28].

Previous study reported that the bioavailability of clozapine (also an atypical antipsychotic) is reduced by pretreatment of GTE in rat [19]. Since QUE is also substrate of CYP 3A enzyme and GTE alter the plasma concentration of CYP3A substrates, this study was designed to study the effect of GTE on QUE pharmacokinetics in rats. 


\section{Materials and Methods}

2.1. Chemicals and Instruments. QUE was received gratis from Ranbaxy Laboratories, India, and risperidone was purchased from Sigma-Aldrich, USA. Green tea leaves extracts (Camellia sinensis) consisting of $14 \%$ polyphenol (44 mg) were obtained from General Nutrition Corporation, USA. Ethanol, ethyl acetate, and methanol were of HPLC grade obtained from Winlab Laboratory whereas formic acid and sodium hydroxide were of analytical grade obtained from BDH Laboratory, England. The apparatus used for analysis of QUE sample consisted of ACQUITY UHPLC system coupled to triple-quadruple tandem mass spectrometer Micromass Quattro Micro (Waters Corp., Milford, MA, USA).

2.2. Animal Experiments. Twelve male Wistar albino rats weighting from 180 to $220 \mathrm{~g}$ were obtained from the Animal Care and Use Centre, College of Pharmacy, King Saud University, Riyadh, Saudi Arabia. In an open level study, rats were randomly divided into two groups (6 in each) and served as control and treatment group, respectively. Rats in treatment group received GTE $(175 \mathrm{mg} / \mathrm{kg}$, oral) [19] for seven days whereas control group received normal saline $(10 \mathrm{~mL} / \mathrm{kg})$. The rats were fasted for at least 12 hours (overnight) before the day of experiment. Blood samples (approximately $0.6 \mathrm{~mL}$ ) were collected from the retroorbital plexus into heparinized microfuge tubes at different time intervals $(0,0.25,0.5,1,1.5$, $2,3,4,6,8$, and $12 \mathrm{~h})$ after administration of QUE $(25 \mathrm{mg} / \mathrm{kg}$, oral) in the morning at 8 a.m. in both groups. Plasma samples were harvested by centrifuging the blood at $15,000 \times \mathrm{g}$ for $10 \mathrm{~min}$ and stored frozen at $-80 \pm 10^{\circ} \mathrm{C}$ until analysis.

\subsection{Determination of QUE Concentration by UPLC MS/MS.}

QUE was determined by the in-house validated UPLCMS/MS method using risperidone as internal standard. The chromatographic separation was performed on Acquity BEH $\mathrm{C}_{18}$ column $(50 \times 2.1 \mathrm{~mm}$, i.d., $1.7 \mu \mathrm{m}$, Waters, USA $)$ maintained at $40^{\circ} \mathrm{C}$ temperature. The mobile phase was composed of ethanol-water-formic acid $(80: 20: 0.1, \mathrm{v} / \mathrm{v} / \mathrm{v})$ at a flow rate of $0.3 \mathrm{~mL} / \mathrm{min}$. Triple-quadruple tandem mass spectrometer equipped with electrospray ionization (ESI) interface was used for analytical detection. The detection was performed in ESI positive mode using multiple reaction monitoring (MRM) by the ion transitions of $\mathrm{m} / z 384.13>$ 253.00 for QUE and $m / z 411.18>191.07$ for IS, having dwell time of $0.161 \mathrm{~s}$. The Mass Lynx software (Version 4.1, SCN 714) was used to control the UHPLC-MS/MS system and data was collected and processed using Target Lynx program. Sample preparation was processed by liquid-liquid extraction method using ethyl acetate as extracting solvent. The dried extracts were reconstituted in $200 \mu \mathrm{L}$ of ethanol and transferred into HPLC vials subjected to the analysis.

2.4. Data Analysis. All values are expressed as the mean \pm standard error. A noncompartmental pharmacokinetic analysis was carried out using WinNonlin software to calculate the $C_{\max }, \mathrm{AUC}, T_{1 / 2}, \lambda z$, CL, and MRT. Statistical differences of the means were assumed to be significant when $P<0.05$ by Student's unpaired $t$-test.
TABLE 1: Pharmacokinetic parameters of QUE in rats after administration of a single oral dose of $25.0 \mathrm{mg} / \mathrm{kg}$ with and without GTE $(175 \mathrm{mg} / \mathrm{kg})($ mean $\pm \mathrm{SE}, n=6)$.

\begin{tabular}{lcc}
\hline Parameters & $\begin{array}{c}\text { QUE alone } \\
(\text { mean } \pm \text { SE) }\end{array}$ & $\begin{array}{c}\text { QUE with GTE } \\
(\text { mean } \pm \text { SE })\end{array}$ \\
\hline$C_{\max }(\mathrm{ng} / \mathrm{mL})$ & $85.40 \pm 34.22$ & $47.49 \pm 15.85^{*}$ \\
$T_{\max }(\mathrm{h})$ & 0.5 & 0.5 \\
$\mathrm{AUC}_{0-24}(\mathrm{ng} \cdot \mathrm{h} / \mathrm{mL})$ & $121.13 \pm 32.59$ & $78.16 \pm 19.96^{*}$ \\
$\mathrm{AUC}_{0-\infty}(\mathrm{ng} \cdot \mathrm{h} / \mathrm{mL})$ & $137.10 \pm 29.16$ & $84.22 \pm 18.91^{*}$ \\
$\lambda z\left(\mathrm{~h}^{-1}\right)$ & $0.24 \pm 0.11$ & $0.34 \pm 0.19$ \\
$T_{1 / 2}(\mathrm{~h})$ & $3.49 \pm 1.69$ & $2.91 \pm 2.22$ \\
$\mathrm{CL}(\mathrm{L} / \mathrm{h} / \mathrm{kg})$ & $0.22 \pm 0.04$ & $0.34 \pm 0.08$ \\
$\mathrm{MRT}(\mathrm{h})$ & $3.50 \pm 1.26$ & $3.21 \pm 1.69$ \\
\hline
\end{tabular}

${ }^{*}$ Significant difference from "QUE alone" group with $t$-test, ${ }^{*} P \leq 0.05$; $C_{\max }$ : maximum plasma concentration; $T_{\max }$ : time to maximum plasma concentration; AUC: area under curve; $\lambda z$ : elimination rate constant; $T_{1 / 2}$ : elimination half-life; CL: clearance; MRT: mean residence time.

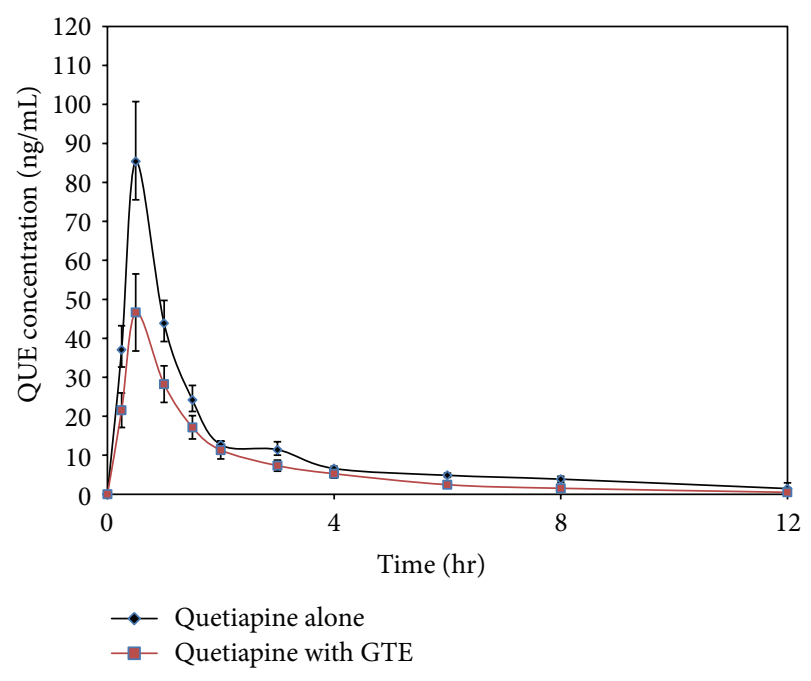

FIGURE 1: Plasma concentration-time curves of quetiapine (mean \pm SE) after a single oral dose of $25 \mathrm{mg} / \mathrm{kg}$ with or without an oral dose of GTE $175 \mathrm{mg} / \mathrm{kg}$.

\section{Results and Discussion}

Pharmacokinetic parameters results and plasma concentrations versus time profile of QUE with and without GTE administration are shown in Table 1 and Figure 1, respectively. Pretreatment with GTE $(175 \mathrm{mg} / \mathrm{kg})$ for seven days resulted in $45 \%$ decrease $(P<0.05)$ in $C_{\max }$ of QUE without any change in $T_{\max }$. Similarly, $\mathrm{AUC}_{0-12}$ and $\mathrm{AUC}_{0-\infty}$ were also decreased $(P<0.05)$ by $35 \%$ and $38 \%$, respectively, compared to control group. However, GTE did not produce any significant changes on $T_{\max }$, elimination half-life, elimination rate constant, and clearance, suggesting that GTE did not affect the elimination of QUE and changes in bioavailability may be attributable to process that occurs in the gut rather than to a modification of systemic clearance. Previous studies showed that the coadministration of GTE and/or EGCG significantly increased the bioavailability of 
simvastatin, 5-FU, diltiazem, irinotecan, and tamoxifen [13, $14,17,18,20]$, whereas it decreased the bioavailability of nadolol and clozapine $[15,19]$ in rats. In consequence to the above reports, our findings indicate that GTE decreases the bioavailability of QUE. GTE increased the bioavailability of tamoxifen, simvastatin, diltiazem, and irinotecan possibly by inhibition of CYP3A enzyme and/or P-gp. Although, like other atypical antipsychotics, QUE is not a substrate of P-gp [29], but it is major substrate of CYP3A4. In spite of that, GTE decreased the plasma concentration of QUE unexpectedly. In nadolol pharmacokinetic interaction study, it was concluded that the decrease in plasma concentration was produced possibly through unknown mechanism, which may include the inhibition of intestinal absorption mediated by uptake transporters, for example, OATP transporter not P-gp, whereas, in clozapine study, decrease in bioavailability was expected due to slight elevation in expression of hepatic CYP1A2m-RNA levels by GTE in rats. QUE is neither a CYP1A2 substrate nor P-gp and OATP transporter; in spite of that, its bioavailability was decreased. But it is also reported that the 7-hydroxy- $\mathrm{N}$ desalkyl quetiapine, a main active metabolite of QUE, was exclusively formed by CYP2D6 [30], and GTE also act as competitive inhibitor of human CYP2B6 and CYP2C8 in addition to CYP3A, especially in the intestine [9]. Hence, further study, in which quetiapine is needed to also be administered intravenously, might help to address this concern.

\section{Conclusions}

In conclusion, pretreatment with GTE significantly decreases the bioavailability of QUE (CYP3A4 substrate) in rats by unknown mechanism. No change in elimination rate and half-life raised the possibility of gut absorption site for GTE and QUE interaction. So, the mechanistic approach for the pharmacokinetic interaction between QUE and GTE needs to be investigated and care may be taken while taking green tea during QUE treatment, which may lead to therapeutic failure.

\section{Conflict of Interests}

Authors have no conflict of interests to disclose.

\section{Acknowledgment}

The authors extend their appreciation to the Deanship of Scientific Research at King Saud University for funding the work through the research group Project no. RG 1435-072.

\section{References}

[1] N. Khan and H. Mukhtar, "Tea polyphenols for health promotion," Life Sciences, vol. 81, no. 7, pp. 519-533, 2007.

[2] C. S. Yang, X. Wang, G. Lu, and S. C. Picinich, "Cancer prevention by tea: Animal studies, molecular mechanisms and human relevance," Nature Reviews Cancer, vol. 9, no. 6, pp. 429439, 2009.
[3] Y. Clement, "Can green tea do that? A literature review of the clinical evidence," Preventive Medicine, vol. 49, no. 2-3, pp. 8387, 2009.

[4] J. J. Johnson, H. H. Bailey, and H. Mukhtar, "Green tea polyphenols for prostate cancer chemoprevention: a translational perspective," Phytomedicine, vol. 17, no. 1, pp. 3-13, 2010.

[5] S. Katiyar, C. A. Elmets, and S. K. Katiyar, "Green tea and skin cancer: photoimmunology, angiogenesis and DNA repair," The Journal of Nutritional Biochemistry, vol. 18, no. 5, pp. 287-296, 2007.

[6] E. Melgarejo, J. L. Urdiales, F. Sánchez-Jiménez, and M. Á. Medina, "Targeting polyamines and biogenic amines by green tea epigallocatechin-3-gallate," Amino Acids, vol. 38, no. 2, pp. 519-523, 2010.

[7] R. J. Moore, K. G. Jackson, and A. M. Minihane, "Green tea (Camellia sinensis) catechins and vascular function," British Journal of Nutrition, vol. 102, no. 12, pp. 1790-1802, 2009.

[8] J. Jodoin, M. Demeule, and R. Béliveau, "Inhibition of the multidrug resistance P-glycoprotein activity by green tea polyphenols," Biochimica et Biophysica Acta-Molecular Cell Research, vol. 1542, no. 1-3, pp. 149-159, 2002.

[9] S. Misaka, K. Kawabe, S. Onoue et al., "Effects of green tea catechins on cytochrome P450 2B6, 2C8, 2C19, 2D6 and 3A activities in human liver and intestinal microsomes," Drug Metabolism and Pharmacokinetics, vol. 28, no. 3, pp. 244-249, 2013.

[10] M. Roth, B. N. Timmermann, and B. Hagenbuch, "Interactions of green tea catechins with organic anion-transporting polypeptides," Drug Metabolism and Disposition, vol. 39, no. 5, pp. 920926, 2011

[11] C. Colalto, "Herbal interactions on absorption of drugs: mechanisms of action and clinical risk assessment," Pharmacological Research, vol. 62, no. 3, pp. 207-227, 2010.

[12] M. I. Netsch, H. Gutmann, C. B. Schmidlin, C. Aydogan, and J. Drewe, "Induction of CYP1A by green tea extract in human intestinal cell lines," Planta Medica, vol. 72, no. 6, pp. 514-520, 2006.

[13] L.-C. Lin, M.-N. Wang, and T.-H. Tsai, "Food-drug interaction of (-)-epigallocatechin-3-gallate on the pharmacokinetics of irinotecan and the metabolite SN-38," Chemico-Biological Interactions, vol. 174, no. 3, pp. 177-182, 2008.

[14] S. Misaka, K. Kawabe, S. Onoue et al., "Green tea extract affects the cytochrome P450 3A activity and pharmacokinetics of simvastatin in rats," Drug Metabolism and Pharmacokinetics, vol. 28, no. 6, pp. 514-518, 2013.

[15] S. Misaka, N. Miyazaki, T. Fukushima, S. Yamada, and J. Kimura, "Effects of green tea extract and (-)-epigallocatechin-3gallate on pharmacokinetics of nadolol in rats," Phytomedicine, vol. 20, no. 14, pp. 1247-1250, 2013.

[16] M. Nishikawa, N. Ariyoshi, A. Kotani et al., "Effects of continuous ingestion of green tea or grape seed extracts on the pharmacokinetics of midazolam," Drug Metabolism and Pharmacokinetics, vol. 19, no. 4, pp. 280-289, 2004.

[17] S.-C. Shin and J.-S. Choi, "Effects of epigallocatechin gallate on the oral bioavailability and pharmacokinetics of tamoxifen and its main metabolite, 4-hydroxytamoxifen, in rats," Anti-Cancer Drugs, vol. 20, no. 7, pp. 584-588, 2009.

[18] J. Qiao, C. Gu, W. Shang et al., "Effect of green tea on pharmacokinetics of 5-fluorouracil in rats and pharmacodynamics in human cell lines in vitro," Food and Chemical Toxicology, vol. 49, no. 6, pp. 1410-1415, 2011. 
[19] E. H. Jang, J. Y. Choi, C. S. Park et al., "Effects of green tea extract administration on the pharmacokinetics of clozapine in rats," Journal of Pharmacy and Pharmacology, vol. 57, no. 3, pp. 311316, 2005.

[20] C. Li and J.-S. Choi, "Effects of epigallocatechin gallate on the bioavailability and pharmacokinetics of diltiazem in rats," Die Pharmazie, vol. 63, no. 11, pp. 815-818, 2008.

[21] A. Chiesa, F. Chierzi, D. De Ronchi, and A. Serretti, "Quetiapine for bipolar depression: a systematic review and meta-analysis," International Clinical Psychopharmacology, vol. 27, no. 2, pp. 7690, 2012.

[22] A. C. Altamura, L. Lietti, C. Dobrea, B. Benatti, C. Arici, and B. Dell'Osso, "Mood stabilizers for patients with bipolar disorder: the state of the art," Expert Review of Neurotherapeutics, vol. 11, no. 1, pp. 85-99, 2011.

[23] E. Vieta, J. Locklear, O. Günther et al., "Treatment options for bipolar depression: a systematic review of randomized, controlled trials," Journal of Clinical Psychopharmacology, vol. 30, no. 5, pp. 579-590, 2010.

[24] C. Lindsay DeVane and C. B. Nemeroff, "Clinical pharmacokinetics of quetiapine: an atypical antipsychotic," Clinical Pharmacokinetics, vol. 40, no. 7, pp. 509-522, 2001.

[25] Agency HoM, "Public assessment report on quitiapine fumarate," DE/H/1458-1459/001-004/DC Quetiapine, Heads of Medicines Agency, Langen, Germany, 2009.

[26] Y. W. J. Wong, C. Yeh, and P. T. Thyrum, "The effects of concomitant phenytoin administration on the steady-state pharmacokinetics of quetiapine," Journal of Clinical Psychopharmacology, vol. 21, no. 1, pp. 89-93, 2001.

[27] H. R. Winter, C. L. DeVane, C. Figueroa et al., "Open-label steady-state pharmacokinetic drug interaction study on coadministered quetiapine fumarate and divalproex sodium in patients with schizophrenia, schizoaffective disorder, or bipolar disorder," Human Psychopharmacology, vol. 22, no. 7, pp. 469476, 2007.

[28] S. W. Grimm, N. M. Richtand, H. R. Winter, K. R. Stams, and S. B. Reele, "Effects of cytochrome P450 3A modulators ketoconazole and carbamazepine on quetiapine pharmacokinetics," British Journal of Clinical Pharmacology, vol. 61, no. 1, pp. 58-69, 2006.

[29] T. Moons, M. de Roo, S. Claes, and G. Dom, "Relationship between P-glycoprotein and second-generation antipsychotics," Pharmacogenomics, vol. 12, no. 8, pp. 1193-1211, 2011.

[30] G. V. Bakken, E. Molden, K. Knutsen, N. Lunder, and M. Hermann, "Metabolism of the active metabolite of quetiapine, $\mathrm{N}$ desalkylquetiapine in vitro," Drug Metabolism and Disposition, vol. 40, no. 9, pp. 1778-1784, 2012. 


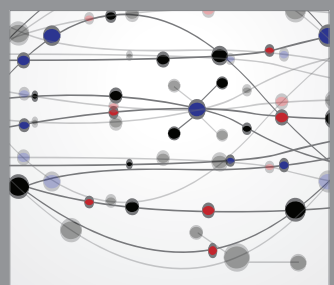

The Scientific World Journal
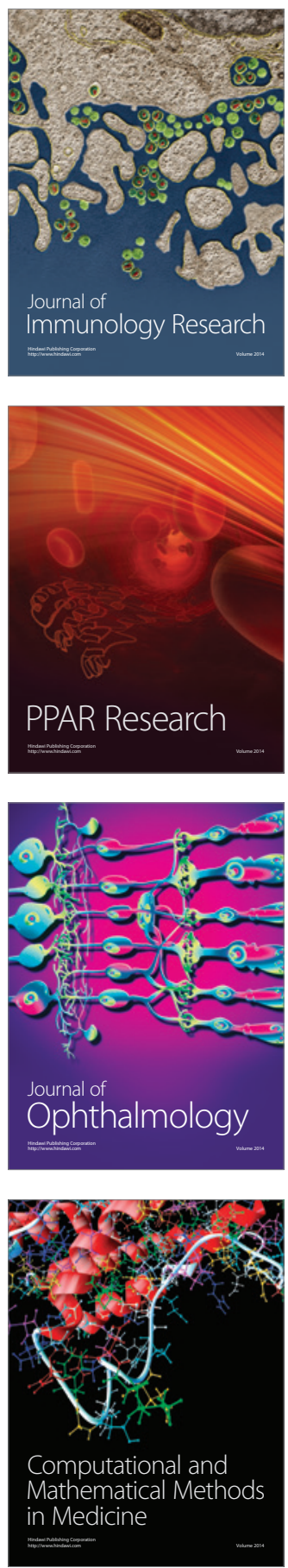

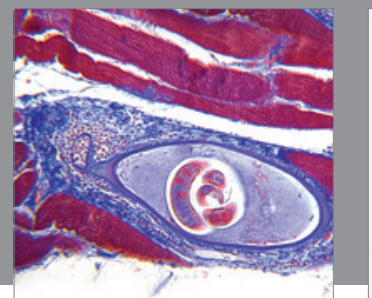

Gastroenterology

Research and Practice
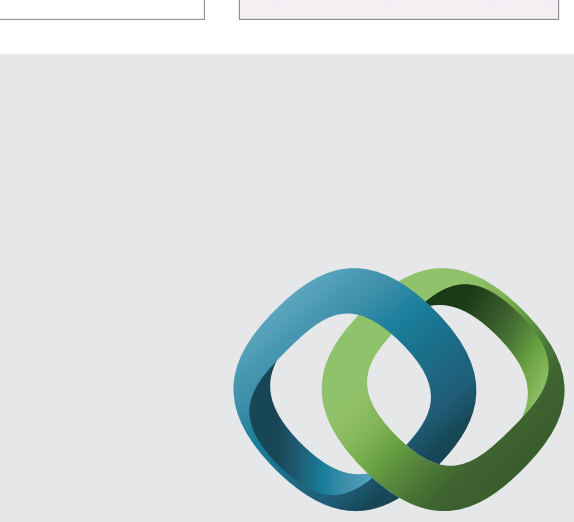

\section{Hindawi}

Submit your manuscripts at

http://www.hindawi.com
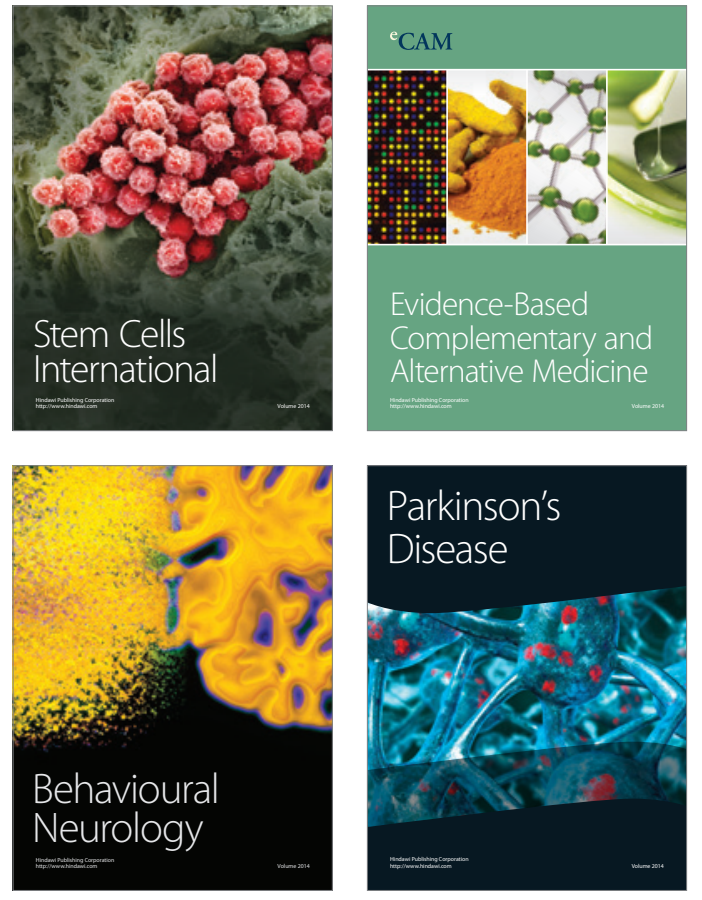
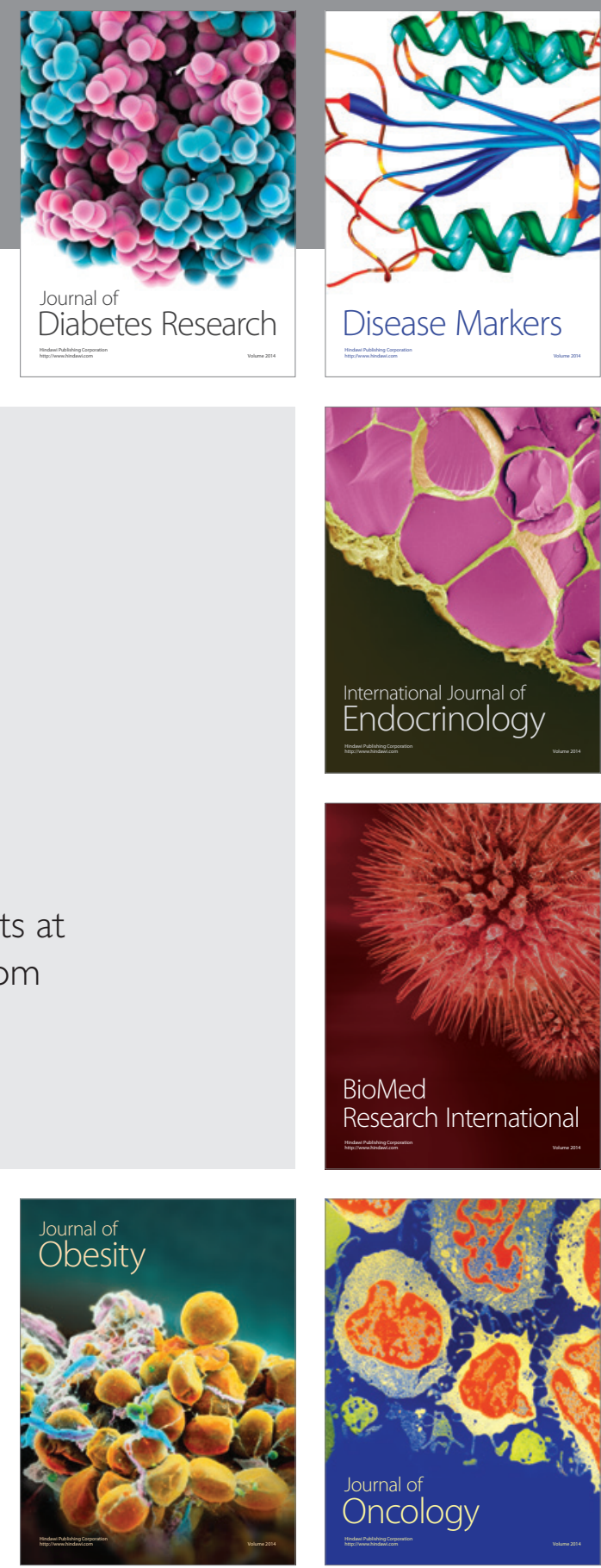

Disease Markers
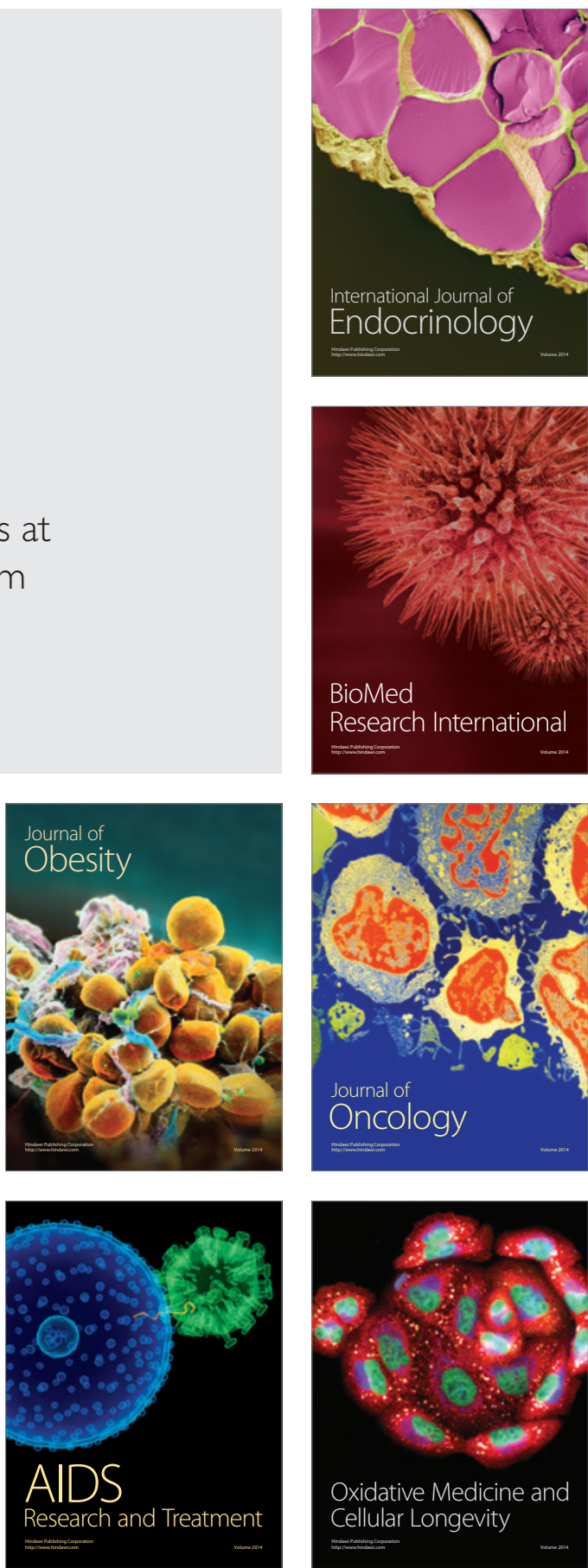